\title{
Characterization of edible swiftlet's nest as a prebiotic ingredient using a simulated colon model
}

\author{
Nur 'Aliah Daud ${ }^{1} \cdot$ Shahrul Razid Sarbini ${ }^{2} \cdot$ Abdul Salam Babji $^{1}$ (I) $\cdot$ Salma Mohamad Yusop ${ }^{1} \cdot$ Seng Joe Lim ${ }^{1}$
}

Received: 8 February 2019 / Accepted: 2 August 2019 / Published online: 17 August 2019

(C) Università degli studi di Milano 2019

\begin{abstract}
Purpose Edible bird's nest (EBN) has been considered as one of the nutritious foods and was also claimed to aid in digestion problems. Potential prebiotic of the EBN for gut health by the presence of glycan within the complex structure of the EBN glycoprotein to date has not been reported. The gut health can contribute to the overall consumers' health in the improvement of the gut beneficial bacterial growth. In this study, the potential prebiotic of the EBN was conducted using a simulation of in vitro human colon model system.

Methods The EBN-extracted glycan and EBN glycoprotein (crude sample) were digested using in vitro oral, gastric and duodenal model system. Prebiotic activities of the undigested EBN glycan and EBN glycopeptide compounds were studied with the fructooligosaccharide as a positive control, using inoculum of $10 \%(\mathrm{w} / \mathrm{v})$ faecal bacteria in the in vitro fermentation system. Result The fermentation of EBN glycan and EBN glycopeptide had shown significant increases of the gut beneficial bacteria and was comparable with fructooligosaccharide fermentation, with each sample presented different profiles of bacterial growth. The fermentation of EBN glycan and EBN glycopeptide demonstrated an increase in the total short-chain fatty acid production, particularly acetate, propionate and butyrate.

Conclusion These findings suggested that the EBN can be functioned as a natural prebiotic upon consumption, thus providing a potential as prebiotic ingredients.
\end{abstract}

Keywords Bioavailability $\cdot$ Bioactive glycan $\cdot$ Prebiotic $\cdot$ Fermentation $\cdot$ Edible bird nest

\section{Introduction}

Dysbiosis is a gut microbial imbalance that has a strong relationship to many illnesses. These illnesses may include obesity, metabolic disorder, irritable bowel syndrome, inflammatory bowel disease and colon cancer (Carding et al. 2015). From the illnesses listed, it shows that the colon health is deemed necessary as much as the overall body health and fitness. Trailing the state of people's health and preferences, the daily diet is adjustable in accordance with the

Abdul Salam Babji

daging@ukm.edu.my

1 Food Science Program, Centre for Biotechnology and Functional Food, Faculty of Science and Technology, Universiti Kebangsaan Malaysia, 43600 Bangi, Selangor, Malaysia

2 Crop Science Department, Faculty of Agriculture, Science and Technology, Universiti Putra Malaysia Bintulu Campus, 97008 Bintulu, Sarawak, Malaysia advancement in production of functional and nutritious food products. Nowadays, functional food products and ingredients have become the leading trends in food and nutraceutical industries (Jiménez-Colmenero et al. 2018). Functional food products containing prebiotic ingredient may influence the gut microbiota while supplying other nutrients for the benefit of consumer's health (Ndeh and Gilbert 2018).

The microbiome in human gut was considered an ancillary organ in contributing important activities to the individual's health (Walker 2017). This consideration is noticeable from the development of gut commensal bacteria that can impact certain health conditions such as strengthening the immune system activity and also their soothing effect of bioactive activities, such as anti-inflammatory and/or anti-cancer. Furthermore, the commensal bacteria are beneficial to the gut in aiding digestion through utilizing the non-digestible compound from human digestion system to proliferate and secure the gut from infectious diseases (Bailey and Cryan 2017). Prebiotic has been described as a non-digestible compound, usually carbohydrates, which act as a food to the 
selected gut commensal bacteria (Hutkins et al. 2016). Hence, the principal concept of prebiotic is essential to leverage the gut bacterial homeostasis.

Edible bird's nest (EBN) from swiftlets has been proven to have high medicinal benefits which include stimulating epidermal growth, preventing viral infection, intensifying immune function, suppressing the generation of TNF- $\alpha$ and alleviating respiratory and digestive problems (Haghani et al. 2016). The EBN is usually consumed in the form of soup. In addition, some studies have shown that the bioactivities such as antioxidant and antiangiotensin-converting enzyme (ACE), in relation to hypertension, are much higher in EBN glycopeptide when digested as compared with the native EBN glycoprotein. While the low-grade EBN such as the waste/residue cannot be moulded into EBN cup-shape after cleaning process, they were converted into extracts and biopeptides which have been incorporated into many forms of food, beverage and nutraceutical products and ingredients. These recent efforts were made to help the EBN industry by improving the usage and availability of EBN in the functional food products.

Mucin glycoprotein of the EBN contains both O- and Nglycosylproteins and represents a natural glycan-rich compound (Wieruszeski et al. 1987; Yagi et al. 2008). These type of complex glycans usually are indigestible by the human stomach digestion system. Human gut bacteria do possess the ability to forage such glycans (Koropatkin et al. 2012; Tailford et al. 2015). In addition, the complex of EBN glycans containing hexose, hexosamine and sialic acid has proximity with human endogenous glycan and milk oligosaccharide (HMO). Both endogenous glycan and HMO were categorized as prebiotic compounds, which showed that the EBN glycan might also have the potential to be a prebiotic compound. This EBN potential prebiotic compound may be available in every form of the EBN consumption, either in the form of soup or functional food product and ingredient. Furthermore, the gut bacterial community relies on several bacterial group and species to produce the set of glycosidases crucial for the degradation of this type of glycan (Tailford et al. 2015). Thus, this study is aimed to characterize the potential prebiotic of the EBN glycans using bacterial mixed culture through specialized in vitro colon model.

\section{Materials and methods}

\section{Materials}

Edible bird nest (EBN), which was produced by the swiftlet from Aerodramus fuciphagus species, was purchased from Mobile Harvester Malaysia Sdn. Bhd. The source of EBN was harvested from swiftlet's houses in Pahang, Malaysia.
Other chemicals and enzymes used in this study were purchased from Sigma-Aldrich, USA. In this study, the native EBN used was soaked in distilled water overnight and further boiled for $30 \mathrm{~min}$ prior further analysis.

\section{Extraction of glycan from edible swiftlet's nest}

The EBN was soaked in distilled water overnight and further boiled for $30 \mathrm{~min}$. The native component of EBN glycoprotein may remain while the structure was opened for enzymatic hydrolysis. The EBN with concentration of $15 \%(\mathrm{w} / \mathrm{v})$ was hydrolysed using $2 \%$ pronase enzyme (w/w) at $\mathrm{pH} 8.0$ to remove protein from the complex glycoprotein of EBN. The hydrolysis process was performed using a waterbath shaker, with agitation of $150 \mathrm{rpm}$ for $24 \mathrm{~h}$. The hydrolysate obtained was filtered through an ultrafiltration membrane MWCO $10 \mathrm{kDa}$ and $3 \mathrm{kDa}$. The remaining solution was collected, freeze and dried. The frozen-dried glycan was stored at room temperature for further analysis.

\section{Characterization of EBN glycan}

The size of the EBN glycan was determined based on the degree of polymerization (DP) process according to the total sugar and reducing sugar contents. The amount of total sugar and reducing sugar contents was quantified using the phenolsulphuric method (Dubois et al. 1956) and dinitrosalicylic acid method (DNS) (Saqib and Whitney 2011), respectively. For total sugar quantification, $50 \mu 1$ sample with concentration of $1 \mathrm{mg} / \mathrm{ml}(\mathrm{w} / \mathrm{v})$ was mixed with $150 \mu \mathrm{l}$ sulphuric acid and $50 \mu \mathrm{l}$ of $5 \%$ phenol $(\mathrm{v} / \mathrm{v})$. The mixture was boiled for $5 \mathrm{~min}$. After cooling to room temperature, the absorbance reading was taken at wavelength $490 \mathrm{~nm}$ using a spectrophotometer (Model UV-160A, Shimadzu, Kyoto, Japan). For quantification of reducing sugar, the DNS reagent was prepared by a mixture of $1 \mathrm{~g}$ DNS and $30 \mathrm{~g}$ sodium potassium tartarate dissolved in $80 \mathrm{ml}$ of $0.5 \mathrm{M}$ sodium hydroxide (w/v) with application of some heat. The reagent then was marked up to $100 \mathrm{ml}$ using distilled water. An amount of $1 \mathrm{ml}$ sample with concentration $1 \mathrm{mg} / \mathrm{ml}$ (w/v) was mixed with $4 \mathrm{ml}$ DNS reagent. The sample mixture was boiled for $5 \mathrm{~min}$. After cooling down to room temperature, the absorbance reading was taken at a wavelength of $540 \mathrm{~nm}$ using a spectrophotometer (Model UV160A, Shimadzu, Kyoto, Japan). The calculation of the degree of polymerization (DP) was based on the following equation (Hayisama-ae et al. 2014):

Degree of polymerization (DP)

$=($ Amount of total sugar $) /($ Amount of reducing sugar $)$ 


\section{In vitro digestibility of EBN glycan and EBN glycoprotein}

The potential digestibility of EBN glycan and EBN native glycoprotein was examined using the simulation method as described by Minekus et al. (2014) with small modifications to best treat the sample. Before and after the in vitro digestion treatment, total protein, peptide, carbohydrate and reducing sugar content were determined by Bradford method (Bradford 1976), o-phthalaldehyde (OPA) method (Church et al. 1983), phenol-sulphuric acid method (Dubois et al. 1956) and DNS method (Saqib and Whitney 2011), respectively. For total protein quantification, $50 \mu \mathrm{l}$ sample in concentration of $1 \mathrm{mg} / \mathrm{ml}(\mathrm{w} / \mathrm{v})$ was mixed with $1.5 \mathrm{ml}$ Bradford reagent and let stand for $10 \mathrm{~min}$ at room temperature. The absorbance reading was taken at $595 \mathrm{~nm}$ using a spectrophotometer (Model UV-160A, Shimadzu, Kyoto, Japan). For peptide quantification, $50 \mu \mathrm{l}$ sample was mixed with $2 \mathrm{ml}$ OPA reagent and left at room temperature for $2 \mathrm{~min}$. The absorbance reading was taken at $340 \mathrm{~nm}$ using a spectrophotometer (Model UV-160A, Shimadzu, Kyoto, Japan).

The stock sample solution was prepared by dissolving the weighed samples in deionized water in the ratio of 1:15 (w/v). Each treatment was performed in triplicate. Casein tryptone and glucose were used as standard compounds to construct standard curve for protein and sugar content calculation. Degree of hydrolysis (DH; \%) for each simulated digestion process was calculated using the following equation:

$\mathrm{DH}(\%)=\left(\left[R_{\mathrm{S}}--R_{0}\right] /\left[T_{\mathrm{s}}--R_{0}\right]\right) \times 100 \ldots \ldots \ldots$

where $R_{\mathrm{S}}$ and $T_{\mathrm{S}}$ are the reducing sugar content and total sugar content after in vitro digestion treatment, respectively. $R_{0}$ is the reducing sugar content before simulated digestion treatment.

$\operatorname{DH}(\%)=\left(\left[P_{\mathrm{s}}--P_{0}\right] /\left[T_{\mathrm{s}}-P_{0}\right]\right) \quad \mathrm{x} 100 \ldots$

where $P_{\mathrm{S}}$ and $T_{\mathrm{S}}$ are the peptide content and total protein content after in vitro digestion treatment, respectively. $P_{0}$ is the peptide content before simulated digestion treatment.

\section{Simulated oral digestion}

Digestibility of EBN glycan and native glycoprotein in oral phase was tested using simulated salivary fluid (SSF; $\mathrm{pH}$ 7.0) which is composed of $3.70 \mathrm{mM}$ potassium dihydrogen phosphate $\left(\mathrm{KH}_{2} \mathrm{PO}_{4}\right), 15.1 \mathrm{M}$ potassium chloride $(\mathrm{KCl}), 0.15 \mathrm{mM}$ magnesium chloride $\left(\mathrm{MgCl}_{2}\right), 13.6 \mathrm{mM}$ sodium bicarbonate $\left(\mathrm{NaHCO}_{3}\right), 0.06 \mathrm{mM}$ ammonium carbonate $\left(\left(\mathrm{NH}_{4}\right) 2 \mathrm{CO}_{3}\right)$, $1.50 \mathrm{mM}$ calcium chloride $\left(\mathrm{CaCl}_{2}\right)$ and salivary $\alpha$-amylase $(150 \mathrm{U} / \mathrm{mL})$. Aliquots of the stock solution $(5.0 \mathrm{~mL})$ were thoroughly mixed with $5.0 \mathrm{~mL}$ of SSF working solution and kept at $37^{\circ} \mathrm{C}$ for $5 \mathrm{~min}$.

\section{Simulated gastric digestion}

Simulated gastric fluid (SGF) was composed of $0.90 \mathrm{mM}$ $\mathrm{KH}_{2} \mathrm{PO}_{4}, 6.90 \mathrm{mM} \mathrm{KCl}, 0.10 \mathrm{mM} \mathrm{MgCl} 2,25.0 \mathrm{mM}$ $\mathrm{NaHCO}_{3}, 0.50 \mathrm{mM}\left(\mathrm{NH}_{4}\right) 2 \mathrm{CO}_{3}, 47.2 \mathrm{mM} \mathrm{NaCl}, 0.15 \mathrm{mM}$ $\mathrm{CaCl}_{2}$ and gastric pepsin $(4000 \mathrm{U} / \mathrm{mL})$. The SGF was adjusted to $\mathrm{pH} 3.0$ using $1.0 \mathrm{M} \mathrm{HCl}$ and mixed with previous oral bolus in equal volume (ratio $1: 1$ ), kept at $37^{\circ} \mathrm{C}$ in a shaker for $2 \mathrm{~h}$.

\section{Simulated intestinal digestion}

Simulated intestinal fluid (SIF) was composed of $0.80 \mathrm{mM}$ $\mathrm{KH}_{2} \mathrm{PO}_{4}, 6.80 \mathrm{mM} \mathrm{KCl}, 0.33 \mathrm{mM} \mathrm{MgCl} 2,85.0 \mathrm{mM}$ $\mathrm{NaHCO}_{3}, 38.4 \mathrm{mM} \mathrm{NaCl}$ and $0.60 \mathrm{mM} \mathrm{CaCl}_{2}$ and trypsin (based on pancreatin $\alpha$-amylase activity at $100 \mathrm{U} / \mathrm{mL}$ ). Aliquots of SIF were adjusted to $\mathrm{pH} 7.0$ using $0.1 \mathrm{M} \mathrm{HCl}$ and mixed with previous gastric bolus, kept in a shaker at $37^{\circ} \mathrm{C}$ for $2 \mathrm{~h}$. The reaction was terminated by boiling in a water bath for $10 \mathrm{~min}$.

\section{In vitro fermentation of EBN glycan and EBN glycopeptides}

\section{Faecal slurry preparation}

Samples from three healthy human volunteers were taken of male gender, aged between 22 and 26 years old. They were confirmed with no history of gastrointestinal disorder such as irritable bowel syndrome, inflammatory bowel disease, peptic ulcers, ulcerative colitis, cancer or Crohn's disease and no records of consuming antibiotics or prebiotic and probiotic supplements for the past 3 months prior to the experiment were obtained. Fresh faecal samples from the selected volunteers were used as the inoculum of bacterial mixed culture. Phosphate-buffered saline (PBS; $\mathrm{pH}$ 7.3) was used to dilute the faecal (ratio 1:10; w/v) and was homogenized in a stomacher (Stomacher 400, Seward, West Sussex, UK) for 2 min at normal speed (265 rpm) (Sarbini et al. 2011).

\section{Basal medium and fermentation vessel preparation}

Fermentation basal medium which consists of $0.01 \mathrm{~g} / \mathrm{l}$ calcium chloride hexahydrate $\left(\mathrm{CaCl}_{2} \cdot 6 \mathrm{H}_{2} \mathrm{O}\right), 0.04 \mathrm{~g} / 1 \mathrm{KH}_{2} \mathrm{PO}_{4}, 0.01 \mathrm{~g} /$ 1 magnesium sulphate heptahydrate $\left(\mathrm{MgSO}_{4} \cdot 7 \mathrm{H}_{2} \mathrm{O}\right), 2 \mathrm{~g} / 1$ $\mathrm{NaHCO}_{3}, 0.1 \mathrm{~g} / 1$ sodium chloride $(\mathrm{NaCl}), 0.5 \mathrm{~g} / 1 \mathrm{~L}$-cysteine hydrochloride, $2 \mathrm{ml} / 1$ Tween $80,2 \mathrm{~g} / 1$ yeast extract, $0.05 \mathrm{~g} / 1$ haemin, $10 \mu \mathrm{l} / \mathrm{l}$ vitamin $\mathrm{K}, 0.5 \mathrm{~g} / \mathrm{l}$ bile salts and $2 \mathrm{~g} / \mathrm{l}$ peptone water was prepared. It was adjusted to $\mathrm{pH} 7.0$, then $4 \mathrm{ml}$ per litre of $0.025 \%(\mathrm{w} / \mathrm{v})$ resazurin solution was added and the medium was autoclaved. Sterile customized glass vessels (100 ml; Soham Scientific, Fordham, UK) of stirred batch culture fermentation were set up and filled with a $45 \mathrm{ml}$ of sterile basal medium ( $50 \mathrm{ml}$ working volume) aseptically. The 
vessels containing basal medium was left gassed with nitrogen gas $(15 \mathrm{ml} / \mathrm{min})$ overnight to create anaerobic conditions (Sarbini et al. 2011).

\section{In vitro colon model fermentation}

The batch culture of in vitro colon model fermentation was performed in the customized vessels, with controlled temperature, $\mathrm{pH}$ and the continuous supply of nitrogen gas, to imitate the distal part of the colon (Sarbini et al. 2011). An amount of $5 \mathrm{ml}$ of fresh faecal slurry was inoculated in each vessel. The substrates of fructooligosaccharide (FOS) as the positive controls, digested EBN glycan and EBN glycopeptide in the form of EBN native glycoprotein produced after going through digestion as the EBN protein can be well digested by human digestion system were added at a concentration of $1 \%(\mathrm{w} / \mathrm{v})$ to each vessel, prior to addition of the faecal slurry. The fermentation vessel's temperature was maintained at $37{ }^{\circ} \mathrm{C}$ using circulating water bath. The $\mathrm{pH}$ value was maintained at 6.8 via $\mathrm{pH}$ controllers (Fermac 260, Electrolab, Gloucestershire, UK), automatically adjusted by adding $0.25 \mathrm{mM}$ sodium hydroxide $(\mathrm{NaOH})$ and hydrochloric acid $(\mathrm{HCl})$ when required. The substrates were fermented anaerobically with constant stirring of the vessels' contents to maintain the anaerobic condition and homogenous suspension. The fermentation process was run for $24 \mathrm{~h}$ and samples from each vessel were taken at 0 , 6,12 and $24 \mathrm{~h}$ for bacterial enumeration and short-chain fatty acid analysis. The experiment was performed in triplicate with a faecal slurry from different donors in each experimental replicate.

\section{Bacterial enumeration}

Synthetic oligonucleotide probes which binds with specific regions of the $16 \mathrm{~S}$ ribosomal ribonucleic acid molecule and labelled with the fluorescent dye cyanine (Cy3) were applied for the specific bacterial groups' enumeration (Table 1). During each sampling time, a sample of $375 \mu$ was taken from each vessel and fixed in the $1125 \mu \mathrm{l}$ of the $4 \%(\mathrm{w} / \mathrm{v})$ paraformaldehyde for $4 \mathrm{~h}$ and maintained at $4{ }^{\circ} \mathrm{C}$. The fixed cells were centrifuged for $5 \mathrm{~min}$ at $13,000 \times g$ and were washed twice in $1 \mathrm{ml}$ of filter-sterilized PBS. An amount of $150 \mu \mathrm{l}$ filtered PBS and $150 \mu \mathrm{l}$ ethanol (99\%) was added in the washed cells and stored at $20^{\circ} \mathrm{C}$ for at least $1 \mathrm{~h}$ before further processing. An applicable volume of PBS was used to dilute the $10 \mu$ l of sample volume to obtain around 20-100 fluorescent cell counts in each field of view. About $20 \mu \mathrm{l}$ of the final solution was added into each well of a 6-well polytetrafluoroethylene/poly-L-lysine-coated slide (Tekdon Inc., Myakka City, FL). The samples were left dried for $15 \mathrm{~min}$ in a drying chamber $\left(46^{\circ} \mathrm{C}\right)$ and dehydrated using alcohol dilution series $(50,80$ and $96 \%$ ethanol; v/v) for $3 \mathrm{~min}$ in each solution, respectively. Excess ethanol on slides was evaporated in the drying oven for $2 \mathrm{~min}$. Hybridization solution $(50 \mu \mathrm{l}$ consisting of $45 \mu \mathrm{l}$ hybridization buffer and $5-\mu l$ probe) was added into each well and left to hybridize for $4 \mathrm{~h}$ in a microarray hybridization incubator (Grant-Boekel, Cambridge, UK). The slides were put in the $50 \mathrm{ml}$ of washing buffer after the hybridization process for $15 \mathrm{~min}$. The slides were then dipped in cold water for a few seconds and dried with compressed air. A $5 \mu \mathrm{l}$ of polyvinyl alcohol mounting medium with 1,4-diazabicyclo(2.2.2)octane (DABCO) was placed in each well, followed by a coverslip on each slide (20 mm; thickness no. 1; VWR, Lutterworth, UK). The slides were examined under an epifluorescence microscope (CX31; Olympus, Tokyo, Japan) using a CX-RFL-2 reflected fluorescence attachment. For each well, the number of cells from 15 different fields of view, under the microscope observation field, was enumerated and averaged as the total counted cells (Sarbini et al. 2011).

Equation for the calculation of total bacteria cells:

$0.8 \times$ average cell count

$\times 8702.47$ (for Brunel microscope)

$\times$ fermentation volume $\times$ dilution used

The number of cells obtained was then converted into a $\log _{10}$ number $\left(\log _{10}\right.$ cells $\left./ \mathrm{ml}\right)$.

\section{Short-chain fatty acid analysis}

Analysis of short-chain fatty acid quantification was performed using HPLC system (Shimadzu SPD-20A) equipped with a UV detector. The column used was C12 HPLC column $(300 \times 7.80 \mathrm{~mm}$; Phenomenex, Cheshire, UK). The eluent used was $2.5 \mathrm{mM}$ sulphuric acid in HPLC-grade water. During each sampling time, $1 \mathrm{ml}$ of sample from each fermentation vessel was taken and further centrifuged at $13,000 \times g$ for $10 \mathrm{~min}$. The supernatants were filtered through a $0.22-\mu \mathrm{m}$ filter unit and $20 \mu \mathrm{l}$ of the filtrate were injected into the HPLC. The HPLC was run at a flow rate of $0.5 \mathrm{ml} / \mathrm{min}$ with heated column of $40{ }^{\circ} \mathrm{C}$. The sample run time was $45 \mathrm{~min}$. Quantification of SCFA was carried out using calibration curves of lactate, acetate, propionate, butyrate, valerate, isobutyrate and iso-valerate at concentrations 12.5, 25, 50, 75 and $100 \mathrm{mM}$ (Sarbini et al. 2011).

\section{Statistical analysis}

Statistical analysis was performed using IBM SPSS Statistics Software version 23. Univariate analysis of variance (ANOVA) and Duncan's test were used to determine the significant difference, where $p<0.05$ is considered as statistically significant. 
Table 1 16S ribosomal RNA oligonucleotide probes used in the present study

\begin{tabular}{|c|c|c|c|}
\hline Probe & Specificity & Sequence & Reference \\
\hline Bif164 & Bifidobacterium spp. & CATCCGGCATTACCACCC & Langendijk et al. (1995) \\
\hline Lab158 & Lactobacillus-Enterococcus & GGTATTAGCAYCTGTTTCCA & Harmsen et al. (1999) \\
\hline Bac303 & $\begin{array}{l}\text { Most Bacteroidaceae and Prevotellaceae, } \\
\text { some Porphyromonadaceae }\end{array}$ & CCAATGTGGGGGACCTT & Manz et al. (1996) \\
\hline Chis 150 & $\begin{array}{l}\text { Most of the bacteria in the Clostridium } \\
\text { histolyticum group (Clostridium clusters I and II) }\end{array}$ & $\begin{array}{l}\text { TTATGCGGTATTAA } \\
\text { TCTYCCTTT }\end{array}$ & Franks et al. (1998) \\
\hline Erec482 & $\begin{array}{l}\text { Most of the Clostridium coccoides-Eubacterium rectale } \\
\text { group (Clostridium clusters XIVa and XIVb) }\end{array}$ & GCTTCTTAGTCARGTACCG & Franks et al. (1998) \\
\hline Prop853 & Clostridium cluster IX & ATTGCGTTAACT CCGGC & Walker et al. (2005) \\
\hline Ato 291 & Atopobium cluster, includes Coriobacterium group & GGTCGG TCTCTCAACCC & Harmsen et al. (2000) \\
\hline Fpra655 & Faecalibacterium prausnitzii and relatives & CGC CTA CCT CTG CAC TAC & Hold et al. (2003) \\
\hline
\end{tabular}

\section{Results and discussion}

\section{EBN glycan characterization}

The purity of collected glycan was determined using Fourier transform infra-red and nuclear magnetic resonance microscopies, which had shown the collected EBN glycan was free from protein, polypeptides and oligopeptides (data not included).The EBN glycan is composed of six types of monosaccharides which are galactose, mannose, fucose, Nacetylglucosamine, $\mathrm{N}$-acetylgalactosamine and $\mathrm{N}$ acetylneuraminic acid (sialic acid) (Wieruszeski et al. 1987; Yagi et al. 2008). The total carbohydrate obtained from EBN glycan was $437.3 \pm 0.1 \mathrm{mg} / \mathrm{g}$, whereas the reducing sugar content was $63.0 \pm 0.02 \mathrm{mg} / \mathrm{g}$. Thus, degree of polymerization (DP) value obtained from the EBN glycan was 7 . The DP value of EBN glycan suits its length based on the findings structure by Wieruszeski et al. (1987) and Yagi et al. (2008), which appeared to have the DP value from 7 to 21 (14 in average). The structures appeared to be branching glycans with two branches in the form of O-glycan or three branches in the form of $\mathrm{N}$-glycan. Both structures contained high galactose and $\mathrm{N}$-acetylhexosamine, $\mathrm{O}$-glycan as the major EBNcontaining structure in comparison with the $\mathrm{N}$-glycan. Inulin can have the DP value from 2 to 60 fructose units (Luo et al. 2017), whereas FOS can have the DP value of 2 to 9 fructose units, and the average of DP FOS is 4 (Zhu et al. 2017). Human milk oligosaccharides (HMOs) which is composed of five types of monosaccharides, such as D-galactose, D-glucose, L-fucose, $\mathrm{N}$-acetylglucosamine and $\mathrm{N}$-acetylneuraminic acid, have the DP value ranging from 3 to 22 (Lie and Pedersen 2016). Thus, the EBN glycan can be considered as an oligosaccharide, just like other prebiotic's oligosaccharides, which might carry prebiotic potential.

\section{Digestibility of EBN glycoprotein and EBN-extracted glycan}

The results of EBN-extracted glycan and glycoprotein (crude EBN) digestion were shown in Table 2. The protein within the glycoprotein structure of the crude EBN was digested significantly $(96.63 \%)$ after going through the in vitro human digestive system. The extracted glycan showed a higher value of carbohydrate digestion (36.37\%) than the crude glycoprotein (21.26\%), releasing some free monosaccharides and much shorter oligosaccharides. However, carbohydrate digestion of both compounds statistically showed no significant difference among each replicate samples $(p<0.05)$. The results suggested an inhibition of the digestive enzymes by the endproducts occurred, with the presence of amino acids, peptides and short oligopeptide chains in the digestion process of crude EBN. The result obtained from the EBN protein digestion was almost similar to the bovine's serum protein that reaches $95 \%$, as reported by Deutz et al. (1995). According to Gardner (1988), almost all-natural proteins (95 to 98\%) can be digested and absorbed in the small intestine. In other study, cheese digestion through simulated human gastrointestinal digestive system was demonstrated and more than $90 \%$ of the protein sequences shown have been digested (61 peptide chains were
Table 2 Digestion values of edible bird nest (EBN) compound from complex glycoprotein and extracted glycan

\begin{tabular}{lllll}
\hline EBN compound & Before digestion (\%) & $\begin{array}{l}\text { Undigested } \\
\text { compound (\%) }\end{array}$ & $\begin{array}{l}\text { Digested } \\
\text { compound (\%) }\end{array}$ & $\begin{array}{l}\text { Degree of } \\
\text { hydrolysis (\%) }\end{array}$ \\
\hline Total protein & $58.60 \pm 0.62$ & $2.02 \pm 0.03$ & $56.58 \pm 0.32$ & 96.55 \\
Total glycan & $21.00 \pm 0.01$ & $16.54 \pm 0.02$ & $4.46 \pm 0.02$ & 21.26 \\
Total glycan extract & $75.50 \pm 0.01$ & $48.04 \pm 0.01$ & $27.46 \pm 0.01$ & 36.37 \\
\hline
\end{tabular}


digested from 63 peptides detected before digestion) (Bottari et al. 2017).

Approximately, the carbohydrate content with the values of $63 \%$ from the EBN-extracted glycan and $78 \%$ from the EBN glycoprotein remains undigested and has a potential to be carried into the gut environment for fermentation by the gut microbiota. The molecular size of the EBN glycoprotein exhibited $140.8 \mathrm{kDa}$ and $64.8 \mathrm{kDa}$, according to Utomo et al. (2014). A study by Xian et al. (2010) showed the molecular size of the digested EBN was reduced to $70 \mathrm{kDa}, 40 \mathrm{kDa}$ and below; whereas some remained stable in larger molecular size. Many studies revealed that components containing $\beta$-structures, such as cellulose and hemicellulose, are resistant to human digestive systems (Dhingra et al. 2012; Sawicki et al. 2017). Proteins with high $\beta$-conformation structures are more stable and resistant to gastrointestinal digestion (Carbonaro et al. 2012). The EBN glycan contained high $\beta$ conformation structure in the form of O-linked and N-linked branch structures (Wieruszeski et al. 1987; Yagi et al. 2008). You et al. (2015) stated that structures of the EBN glycan are like mammalian fibres, where most fibres are undigestible through the human digestive systems (Dhingra et al. 2012).

\section{Growth profiles of Bifidobacteria, Lactobacilli-Enterococci, Bacteroides-Prevotella and Clostridiumhistolyticum}

The growth of Bifidobacteria, Lactobacilli-Enterococci, Bacteroides-Prevotella and Clostridium histolyticum group in $\mathrm{pH}$-controlled batch cultures at $0,6,12$ and $24 \mathrm{~h}$ of fermentation was shown as in Fig. 1. The growth of Bifidobacteria was increased significantly in the presence of EBN glycopeptide, EBN glycan and FOS, compared with the growth without substrate, with FOS showing much significant growth than others, where $p<0.05$ (Fig. 1(a)). The growth of Lactobacilli-Enterococci was increased in the presence of EBN glycopeptide, EBN glycan and FOS, higher than without substrate, but not significant at $p<0.05$ (Fig. 1(b)). Every tested substrate improved the growth of BacteroidesPrevotella significantly compared with those without substrates and the Bacteroides-Prevotella growth in EBN glycopeptide and EBN glycan was comparable with the growth in FOS at $p<0.05$ (Fig. 1(c)). The improved growth of the beneficial commensal gut bacteria may suppress the growth of potentially pathogen bacteria during the competition when using the presented substrate, whereas the beneficial of commensal bacteria may pre-dominate the bacterial growth. In this study, the result was shown in the decrease of Clostridium histolyticum (a key group of major pathogenic bacteria resides in the human gut) as in Fig. 1(d). The growth of the Clostridium histolyticum was dropped in the presence of EBN glycopeptide, EBN glycan and FOS after $6 \mathrm{~h}$ of fermentation, where a slow and continuous decrease was observed in the presence of FOS.

In comparison with the commercial prebiotic FOS, the Bifidobacterial growth profiles from EBN glycan fermentation were significant than EBN glycopeptide and almost comparable with the FOS $(p<0.05)$. On the other hand, EBN glycopeptide fermentation had increased the BacteroidesPrevotella population much higher than the FOS fermentation (but not significant at $p<0.05$ ), probably due to the presence of peptide in the EBN glycopeptide chain. The high growth of Bacteroides-Prevotella in the presence of EBN glycopeptide is supported by Aguirre et al. (2016) which proved high growth of Bacteroides in protein enrichment media compared with carbohydrate enrichment media. In this study, Bacteroides-Prevotella population was also well increased in both FOS and EBN glycan fermentation. This might be due to the privilege of the Bacteroides population which has a flexible capability to change its metabolism between carbohydrate and protein or glycoprotein subjected to the nutrient availability. In addition, peptidase activity had been highly observed among Bacteroides spp. from human faeces and usually found in abundance in the high protein diet compared with high carbohydrate diet (Zimmer et al. 2012). Hence, Bacteroides can grow well in both carbohydrate and protein substrates and in some cases, much better in a highly protein diet.

Prebiotics such as FOS, GOS, inulin and the commonly known lactulose have a selective effect by increasing the number of Bifidobacteria and reducing the number of pathogenic bacteria groups (Liu et al. 2017). In silico genomic analysis with the study of genomic function of Bifidobacterium bifidum sequence had depicted the genetic code that served to metabolism of glycoprotein. Enzymes encoded by these genes had included the extracellular sialidase and fucosidase, endo- $\alpha-\mathrm{N}$-acetylgalactosaminidase, $\mathrm{N}$-acetyl- $\beta$ hexosaminidase and $\beta$-galactosidase (Turroni et al. 2010). In addition, carbohydrates with long chains required longer fermentation times (Cardelle-Cobas et al. 2011; HernándezHernández et al. 2012). However, the EBN substrate in this study showed the opposite result, with the growth of Lactobacilli-Enterococci higher than FOS (shorter oligosaccharides with DP value of 4 in average) within the 6-h fermentation (lag phase) of Lactobacilli-Enterococci growth profile, which could be due to its longer chain of EBN glycan based on the number of DP, but packed in the form of branches (Wieruszeski et al. 1987; Yagi et al. 2008). However, overall Lactobacilli-Enterococci growth in the fermentation of the EBN substrate and FOS had shown no significant difference $(p<0.05)$.

Prevotella sp.is a part of the commensal bacteria that seldom caused infection, except for some species such as $P$. copri and $P$. stercorea which once involved in opportunistic infections, have a strong relationship with the dysbiosis and can cause inflammation (Larsen 2017). The growth of Bacteroides 


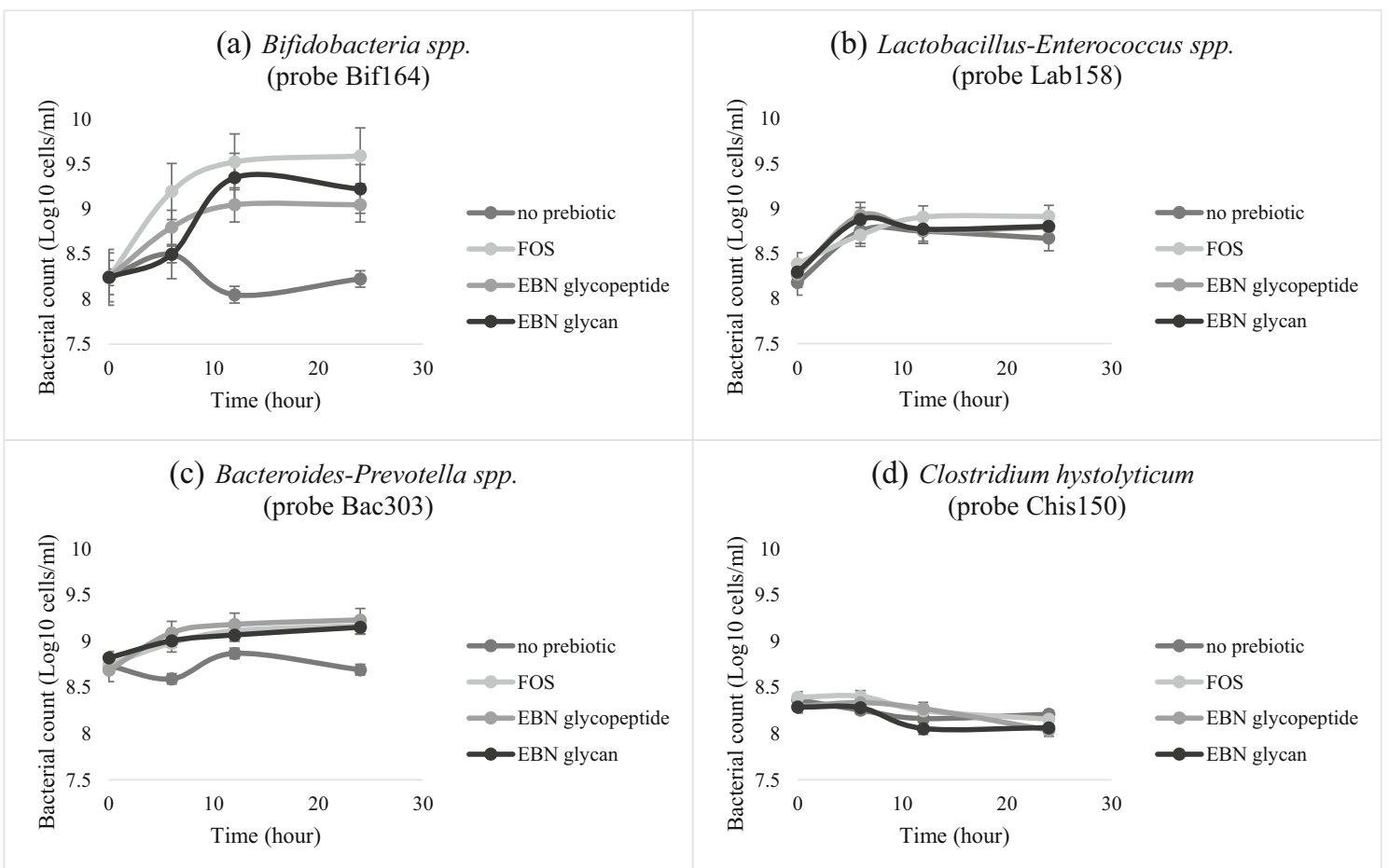

Fig. 1 Growth profile of selected bacterial population (probes bif164, lab158, bac303 and chis150) in pH-controlled batch culture fermentation of different substrates at $0,6,12$ and $24 \mathrm{~h}$

may produce a polysaccharide capsule-containing cephalosporinase (functioned in neutralizing bacterial toxin) which can assist to restore the gut bacterial homeostasis and improve immuno-modulation function, and further assist to remove pathogenic bacteria (Turroni et al. 2014). Acidic environment in the human gut can inhibit the growth of pathogenic bacteria and some commensal bacteria such as the Bacteroides, where Bifidobacteria is much more resistant and less affected (Van der Meulen et al. 2006). An in vitro competitive study by Yu et al. (2012) had demonstrated the Bifidobacterium longum and Bacteroides sp. may utilize their ability to use glycoprotein in the form of milk to overtake the growth of potential pathogenic bacteria commonly found in the human gut, such as Escherichia coli (exist in a small number) and C. perfringens.

\section{Growth profiles of Atopobium spp., Faecalibacterium prausnitzii and commensal Clostridium group of bacteria}

Atopobium spp. is one of the predominant and prevalent bacteria residing in human gut although to date, little information is known about it. However, some studies have been reported on the Atopobium population showing an inverse correlation with inflammatory bowel disease (Takaishi et al. 2008) and a potential to induce apoptosis in colonic cancer cells (Altonsy et al. 2010). In this study, the Atopobium population in both EBN glycopeptide and EBN glycan fermentation exhibited increased and prolonged growth as observed in the EBN glycan fermentation, as illustrated in Fig. 2 (c). The improvement of Atopobium population can be used as an indicator for healthy growth of commensal gut bacteria. Faecalibacterium prausnitzii, being the first identified anti-inflammatory commensal bacterium (LeBlanc et al. 2017), also exhibited an improved and continuous growth profile in the presence of both EBN glycopeptide and EBN glycan, as shown in Fig. 2 (d).

Commensal Clostridium group such as Eubacterium rectale cluster XIVa and XIVb (butyrate-producing group) and Clostridium cluster IX (propionate-producing group) exhibited a similar growth profile in each EBN glycopeptide and EBN glycan, respectively, shown in Fig. 2 (a and b, respectively). Both Clostridium groups showed a high growth within the $6 \mathrm{~h}$ of fermentation with the EBN glycan and they both have continuous growth profile after 12-h fermentation compared with the EBN glycopeptide. The EBN glycopeptide has a similar commensal Clostridial growth profile with FOS. However, the overall growth of the commensal Clostridia (butyrate- and propionate-producing group) showed no significant difference among the tested substrates when $p<0.05$. The major commensal Clostridia involved in the gut homeostasis are usually from Clostridium cluster XIVa (butyrateproducers) and Clostridium cluster IX (propionateproducers) (Lopetuso et al. 2013). In a co-culture study using $B$. longum and $E$. rectale in the presence of arabinoxylanoligosaccharides, the mixed culture exhibited interactions of 
(a) Clostridium clusters XIVa and XIVb (probe Erec482)

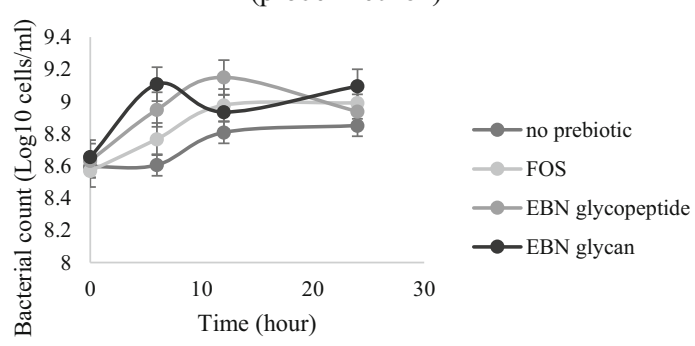

(c) Atopobium-Coriobacterium spp. (probe Ato291)

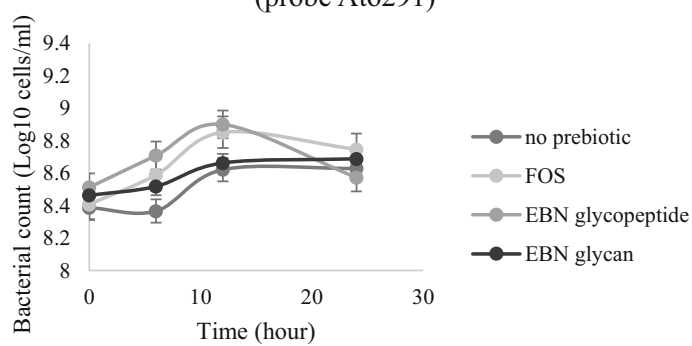

(b) Clostridium cluster IX (probe Prop853)

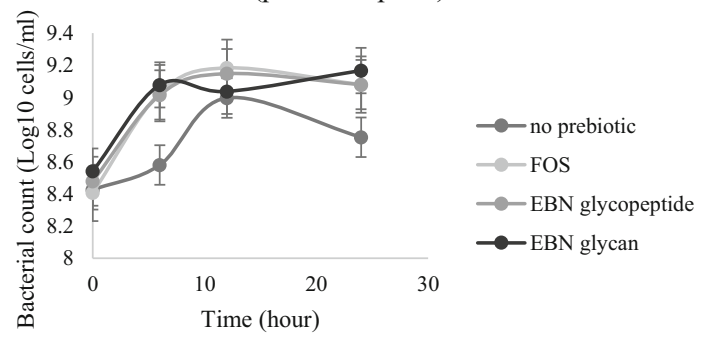

(d) Faecalibacterium prausnitzii (probe Fpra655)

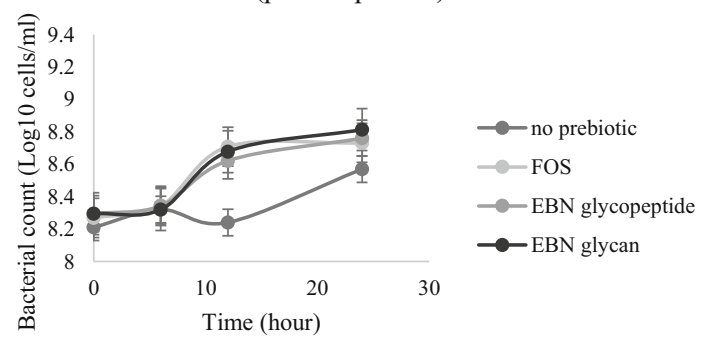

Fig. 2 Growth profile of selected bacterial population (probes ato291, erec482, prop853 and fpra655) in pH-controlled batch culture fermentation of different substrates at $0,6,12$ and $24 \mathrm{~h}$

mutual cross-feeding mechanisms with $B$. longum which showed bifidogenic effect to produce acetate and E. rectal which showed butyrogenic effect to convert acetate into butyrate (Rivière et al. 2016). The study was an evidence to show that the improvement of commensal Clostridial growth, as in the fermentation of both EBN and FOS, can restore the gut bacterial homeostasis, which can positively contribute a treatment in dysbiosis condition and liberated into normal distribution of gut microbiota (Lopetuso et al. 2013).

\section{Fermentation product—short-chain fatty acid}

Gut bacterial fermentation produced short-chain fatty acid (SCFA) with a major product of acetate $(\mathrm{C} 2)$, propionate (C3) and butyrate (C4) depending on the type of substrate (Tailford et al. 2015). Figure 3 presented the amount of lactate and SCFA products from bacterial fermentation in the $\mathrm{pH}$ controlled batch cultures at $0,6,12$ and $24 \mathrm{~h}$. A continuous drop of lactate was observed in every batch culture, while lactate product was elevated during the last 12-h fermentation in the presence of FOS and EBN glycan, as well as without substrate. Lactate, being a part of the fermentation product, functioned as the fuel for the bacterial growth, as well as some of the acetate product (SCFA product). The production of acetate was significant in the fermentation of EBN glycopeptide, followed by FOS and EBN glycan $(p<0.05)$. Based on Fig. 3, the major products of acetate, propionate and butyrate were observed from fermentation of EBN glycopeptide and FOS, whereas a major amount of acetate and propionate with a small amount of butyrate from the EBN glycan fermentation process. The difference in the formation of butyrate within the EBN glycan fermentation is probably due to the difficulty in the breakdown of the complex glycan (Koropatkin et al. 2012). The fermentation of EBN glycopeptide and EBN glycan had increased a significant amount of isobutyrate compared with the FOS and without substrate, while fermentation of EBN glycopeptide contributed another significant amount of iso-valerate product compared with other substrates $(p<0.05)$. However, the total amount of isobutyrate in every tested substrate after 24-h fermentation showed no significant difference $(p<0.05)$. The total SCFA from every substrate after 24-h fermentation process is shown in Fig. 4.

Production of acetate is much more general among bacterial groups, whereas production of lactate, propionate and butyrate was shown to be more highly substrate specific (Morrison and Preston 2016). Bacterial species which are dominated by Faecalibacterium prausnitzii, Eubacterium rectale, Eubacterium hallii and Ruminococcus bromii were shown to be responsible to produce butyrate (Louis et al. 2010). The decrease in lactate content indicated that butyrate-producing bacteria had utilized some of the presented lactate being converted into butyrate product (Belenguer et al. 2006). Lactate is also actively utilized by other gut bacteria in a cross-feeding mechanism and contributes to the production of acetate, propionate and butyrate (Morrison and Preston 2016). Acetate production typically accounted for 30-54\% of the total SCFA product, depending on the condition of the gut and the availability of substrate. 


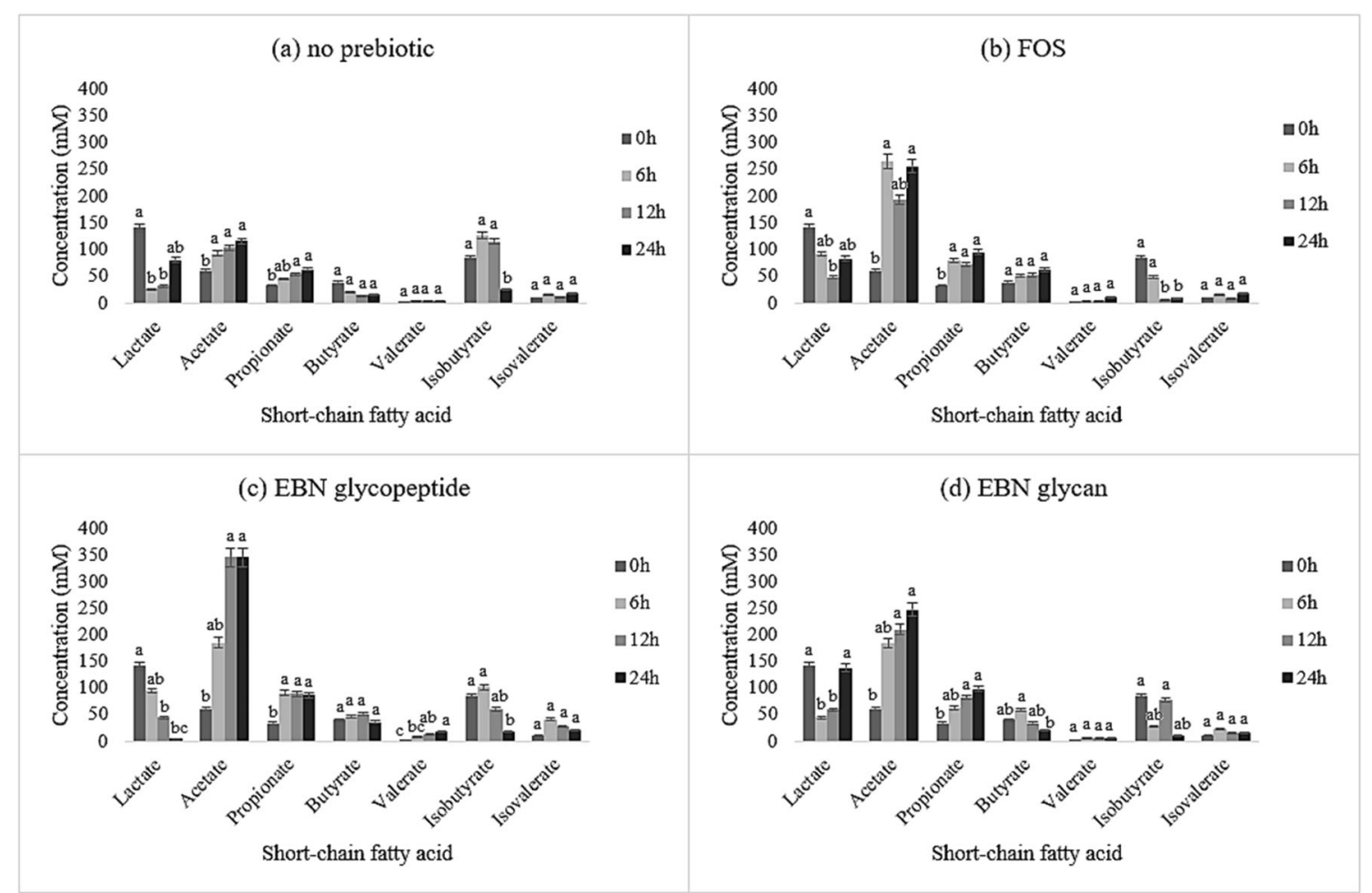

Fig 3 Amount of short-chain fatty acids (SCFA) and lactic acid concentrations in different substrates fermentation at $0,6,12$ and $24 \mathrm{~h}$. a-b small alphabet showed a significant difference between time of fermentation $(p<0.05)$

On the other view, the increased of isobutyrate in the fermentation of EBN glycan and glycopeptide showed the increased of obligate anaerobic bacteria. The obligated bacteria convert butyrate into isobutyrate which functioned as an ecological balance (Matthies and Schink 1992).The increased of acetate in the fermentation of EBN glycopeptide (within the first and second of 6-h fermentation in respect to their lag and $\log$ phase, respectively) and EBN glycan (after the first of 6-h fermentation, the lag phase) in stages showed much stable bacterial growth than the fermentation of FOS and could present the stability of bacterial population during the particular growth phases. Furthermore, a reversible isomerization process between butyrate and isobutyrate may occur under methanogenic condition (Angelidaki and Ahring 1995). The methanogenic bacteria support the growth of other bacteria in the communities by utilizing other limited product such as
Fig. 4 Total amount of shortchain fatty acids (SCFA) concentrations in different substrate fermentation after $24 \mathrm{~h}$ of fermentation process. $\mathrm{a}-\mathrm{b}$ small alphabet showed a significant difference between substrates $(p<0.05)$

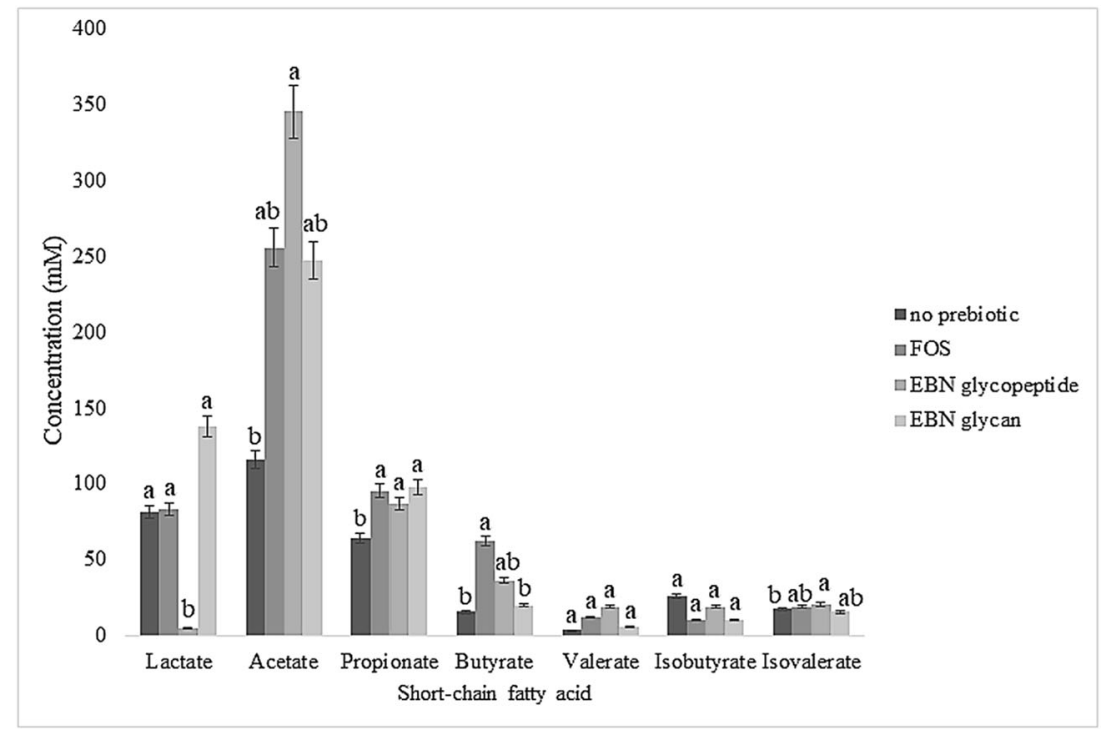


hydrogen, carbon dioxide and formate as their substrates to stimulate the metabolism of other bacteria (Whitman et al. 2006). The shifts of butyrate production into isobutyrate in the EBN glycan fermentation which was observed at 12-h fermentation log phase of bacterial growth could also be due to the involvement of the methanogenic bacteria.

The production of propionate with the fermentation of carbohydrate complex under limited source of carbon generally needs a longer time of generation (Rios-Covian et al. 2017). In this study, the propionate was increased in stages with the fermentation of EBN glycan, whereas for EBN glycopeptide the increment only occurred in the first of 6-h fermentation and for FOS the increment only occurred in the first and last of 6-h fermentation. The result showed that the EBN glycan was hard to be utilized as compared with the EBN glycopeptide which contained oligopeptide or amino acid in the complex glycopeptide and FOS. Amino acid fermentation can contribute to the production of acetate and propionate (Morrison and Preston 2016), which also highlighted the significant increase in acetate product with the fermentation of EBN glycopeptide as compared with FOS and EBN glycan $(p<0.05)$. In addition, a diversity in the complex structure of glycan such as the extracted EBN glycan which usually exists in the secreted mucus of the colon cell wall would function to hinder microbial species from becoming too competent during harvesting these structures, where many types of bacterial species can dynamically grow, thus protecting the integrity of this important barrier in the gut environment (Koropatkin et al. 2012).

\section{Conclusion}

This study has characterized the growth of the gut beneficial bacteria through in vitro fermentation in the presence of EBN glycopeptide and EBN glycan which could suppress the growth of potential pathogenic bacteria, Clostridium histolyticum. The EBN glycopeptide and EBN glycan fermentation resulted in significant levels of acetate and propionate products, while the EBN glycopeptide fermentation also produced a significant amount of butyrate. The SCFA products obtained are beneficial for human health and well-being. The fermentation of EBN glycopeptide and EBN glycan has contributed different profiles of the gut bacterial growth that may have different effects in the human gut environment. The EBN glycan can be used as an extracted prebiotic ingredient with much specificity for bifidogenic effect by utilizing the low-grade EBN which is referred to as a waste/residue from the EBN industries. Meanwhile, under normal consumption of the EBN glycoprotein, the undigested compound of the EBN glycopeptide may brought the prebiotic effect in the gut environment. These new properties may contribute to the intake of the EBN as a functional food and a returning benefit to the EBN industries.
Acknowledgements The authors would like to thank the participating students from Universiti Putra Malaysia Campus Bintulu for their voluntary participation.

Funding This work was supported by CoE-Swiftlet Project under Grant (6371400-10301-(PN3): UPM/ST-2016-013: UKM).

\section{Compliance with ethical standards}

Conflict of interest The authors declare that they have no conflicts of interest.

Research involving human participants and/or animals This article does contain studies with human participants performed by the authors.

Informed consent No ethical approval was obtained because this study did not involve laboratory animals and only involved non-invasive procedures. Informed consent was obtained from all individual participants included in the study.

\section{References}

Aguirre M, Eck A, Koenen ME, Savelkoul H, Budding AE, Venema K (2016) Diet drives quick changes in the metabolic activity and composition of human gut microbiota in a validated in vitro gut model. Res Microbiol 167:114-125

Altonsy MO, Andrews SC, Tuohy KM (2010) Differential induction of apoptosis in human colonic carcinoma cells (Caco-2) by Atopobium, and commensal, probiotic and enteropathogenic bacteria: mediation by the mitochondrial pathway. Int J Food Microbiol 137:190-203

Angelidaki I, Ahring BK (1995) Isomerization of n-andi-butyrate in anaerobic methanogenic systems. Antonie Van Leeuwenhoek 68:285291

Bailey MT, Cryan JF (2017) The microbiome as a key regulator of brain, behavior and immunity: commentary on the 2017 named series. Brain Behav Immun 66:18-22

Belenguer A, Duncan SH, Calder AG, Holtrop G, Louis P, Lobley GE, Flint HJ (2006) Two routes of metabolic cross-feeding between Bifidobacterium adolescentis and butyrate-producing anaerobes from the human gut. J Appl Environ Microbiol 72:3593-3599

Bottari B, Quartieri A, Prandi B, Raimondi S, Leonardi A, Rossi M, Ulrici A, Gatti M, Sforza S, Nocetti M, Amaretti A (2017) Characterization of the peptide fraction from digested Parmigiano Reggiano cheese and its effect on growth of lactobacilli and bifidobacteria. Int J Food Microbiol 255:32-41

Bradford MM (1976) A rapid and sensitive method for the quantitation of microgram quantities of protein utilizing the principle of protein-dye binding. Anal Biochem 72:248-254

Carbonaro M, Maselli P, Nucara A (2012) Relationship between digestibility and secondary structure of raw and thermally treated legume proteins: a Fourier transform infrared (FT-IR) spectroscopic study. Amino Acids 43:911-921

Cardelle-Cobas A, Corzo N, Olano A, Peláez C, Requena T, Ávila M (2011) Galactooligosaccharides derived from lactose and lactulose: influence of structure on Lactobacillus, Streptococcus and Bifidobacterium growth. Int J Food Microbiol 149:81-87

Carding S, Verbeke K, Vipond DT, Corfe BM, Owen LJ (2015) Dysbiosis of the gut microbiota in disease. Microb Ecol Health Dis 26:26191

Church FC, Swaisgood HE, Porter DH, Catignani GL (1983) Spectrophotometric assay using o-phthaldialdehyde for 
determination of proteolysis in milk and isolated milk proteins. $\mathrm{J}$ Dairy Sci 66:1219-1227

Deutz NEP, Ten Have GAM, Soeters PB, Moughan PJ (1995) Increased intestinal amino-acid retention from the addition of carbohydrates to a meal. Clin Nutr 14:354-364

Dhingra D, Michael M, Rajput H, Patil RT (2012) Dietary fibre in foods: a review. J Food Sci Technol 49:255-266

Dubois M, Gilles KA, Hamilton JK, Rebers PT, Smith F (1956) Colorimetric method for determination of sugars and related substances. Anal Chem 28:350-356

Franks AH, Harmsen HJ, Raangs GC, Jansen GJ, Schut F, Welling GW (1998) Variations of bacterial populations in human feces measured by fluorescent in situ hybridization with group-specific 16S rRNAtargeted oligonucleotide probes. Appl Environ Microbiol 64: 33363345

Gardner ML (1988) Gastrointestinal absorption of intact proteins. Annu Rev Nutr 8:329-350

Haghani A, Mehrbod P, Safi N, Aminuddin NA, Bahadoran A, Omar AR, Ideris A (2016) In vitro and in vivo mecanism of immunomodulatory and antiviral activity of Edible Bird's Nest (EBN) against influenza A virus (IAV) infection. J Ethnopharmacol 185: 327-340

Hayisama-Ae W, Kantachote D, Bhongsuwan D, Nokkaew U, Chaiyasut C (2014) A potential synbiotic beverage from fermented red seaweed (Gracilariafisheri) using Lactobacillus plantarum DW12. Int Food Res J 21:1789-1796

Harmsen HJ, Elfferich P, Schut F, Welling GW (1999) A 16S rRNAtargeted probe for detection of lactobacilli and enterococci in faecal samples by fluorescent in situ hybridization. Microbiol Ecology in Health and Disease 11: 3-12

Harmsen HJ, Wildeboer-Veloo AC, Grijpstra J, Knol J, Degener JE, Welling GW (2000) Development of 16S rRNA-based probes for Coriobacterium group and the Atopobium cluster and their application for enumeration of Coriobacteriaceae in human feces from volunteers of different age groups. Appl Environ Microbiol 66: 45234527

Hernández-Hernández O, Muthaiyan A, Moreno FJ, Montilla A, Sanz ML, Ricke SC (2012) Effect of prebiotic carbohydrates on the growth and tolerance of Lactobacillus. Food Microbiol 30:355-361

Hold GL, Schwiertz A, Aminov RI, Blaut M, Flint HJ (2003) Oligonucleotide probes that detect quantitatively significant groups of butyrateproducing bacteria in human feces. Appl Environ Microbiol 69: 4320-4324

Hutkins RW, Krumbeck JA, Bindels LB, Cani PD, Fahey G Jr, Goh YJ, Hamaker B, Martens EC, Mills DA, Rastal RA, Vaughan E (2016) Prebiotics: why definitions matter. Curr Opin Biotechnol 37:1-7

Jiménez-Colmenero F, Cofrades S, Herrero AM, Ruiz-Capillas C (2018) Implications of domestic food practices for the presence of bioactive components in meats with special reference to meat-based functional foods. Crit Rev Food Sci Nutr 58(14):2334-2345

Koropatkin NM, Cameron EA, Martens EC (2012) How glycan metabolism shapes the human gut microbiota. Nat Rev Microbiol 10:323

Langendijk PS, Schut F, Jansen GJ, Raangs GC, Kamphius GR, Wilkinson MH, Welling GW (1995) Quantitative fluorescence in situ hybridization of Bifidobacterium spp. with genus-specific 16S rRNA-targeted probes and its application in fecal samples. Appl Environ Microbiol 61: 3069-3075

Larsen JM (2017) The immune response to Prevotella bacteria in chronic inflammatory disease. Immunology 151:363-374

LeBlanc JG, Chain F, Martín R, Bermúdez-Humarán LG, Courau S, Langella P (2017) Beneficial effects on host energy metabolism of short-chain fatty acids and vitamins produced by commensal and probiotic bacteria. Microbial Cell Fact 16:79

Lie A, Pedersen LH (2016) Analysis of human milk oligosaccharides using high-performance anion-exchange chromatography with pulsed amperometric detection. In: 11th Danish Conf Biotechnol Mol Biol, Denmark.
Liu F, Li P, Chen M, Luo Y, Prabhakar M, Zheng H, He Y, Qi Q, Long H, Zhang Y, Sheng H (2017) Fructooligosaccharide (FOS) and galactooligosaccharide (GOS) increase bifidobacterium but reduce butyrate producing bacteria with adverse glycemic metabolism in healthy young population. Scientific Reports 7: 11789

Lopetuso LR, Scaldaferri F, Petito V, Gasbarrini A (2013) Commensal Clostridia: leading players in the maintenance of gut homeostasis. Gut Pathog 5:23

Louis P, Young P, Holtrop G, Flint HJ (2010) Diversity of human colonic butyrate-producing bacteria revealed by analysis of the butyrylCoA: acetate CoA-transferase gene. Environ Microbiol 12:304-314

Luo D, Li Y, Xu B, Ren G, Li P, Li X, Han S, Liu J (2017) Effects of inulin with different degree of polymerization on gelatinization and retrogradation of wheat starch. Food Chem 229:35-43

Manz W, Amann R, Ludwig W, Vancanneyt M, Schleifer KH (1996) Application of a suite of $16 \mathrm{~S}$ rRNA-specific oligonucleotide probes designed to investigate bacteria of the phylum cytophagaflavobacter-bacteroides in the natural environment. Microbiology 142: $1097-1106$

Matthies C, Schink B (1992) Reciprocal isomerization of butyrate and isobutyrate by the strictly anaerobic bacterium strain WoG13 and methanogenic isobutyrate degradation by a defined triculture. Appl Environ Microbiol 58:1435-1439

Minekus M, Alminger M, Alvito P, Ballance S, Bohn T, Bourlieu C, Carriere F, Boutrou R, Corredig M, Dupont D, Dufour C (2014) A standardised static in vitro digestion method suitable for food-an international consensus. Food Funct 5:1113-1124

Morrison DJ, Preston T (2016) Formation of short chain fatty acids by the gut microbiota and their impact on human metabolism. Gut Microbes 7:189-200

Ndeh D, Gilbert HJ (2018) Biochemistry of complex glycan depolymerisation by the human gut microbiota. FEMS Microbiol Rev 42:146-164

Rios-Covian D, Salazar N, Gueimonde M, de los Reyes-Gavilan CG (2017) Shaping the metabolism of intestinal Bacteroides population through diet to improve human health. Front Microbiol 8:376

Rivière A, Selak M, Lantin D, Leroy F, De Vuyst L (2016) Bifidobacteria and butyrate-producing colon bacteria: importance and strategies for their stimulation in the human gut. Front Microbiol 7:979

Saqib AAN, Whitney PJ (2011) Differential behaviour of the dinitrosalicylic acid (DNS) reagent towards mono-and di-saccharide sugars. Biomass Bioenergy 35:4748-4750

Sarbini SR, Kolida S, Naeye T, Einerhand A, Brison Y, Remaud-Simeon M, Monsan P, Gibson GR, Rastall RA (2011) In vitro fermentation of linear and $\alpha-1,2$ branched dextrans by the human faecal microbiota. Appl Environ Microbiol 77: 5307-5315

Sawicki CM, Livingston KA, Obin M, Roberts SB, Chung M, McKeown NM (2017) Dietary fiber and the human gut microbiota: Application of evidence mapping methodology. Nutrients 9:125

Tailford LE, Crost EH, Kavanaugh D, Juge N (2015) Mucin glycan foraging in the human gut microbiome. Front Genet 6:81

Takaishi H, Matsuki T, Nakazawa A, Takada T, Kado S, Asahara T, Kamada N, Sakuraba A, Yajima T, Higuchi H, Inoue N (2008) Imbalance in intestinal microflora constitution could be involved in the pathogenesis of inflammatory bowel disease. Int J Med Microbiol 298:463-472

Turroni F, Bottacini F, Foroni E, Mulder I, Kim JH, Zomer A, Sánchez B, Bidossi A, Ferrarini A, Giubellini V, Delledonne M (2010) Genome analysis of Bifidobacterium bifidum PRL2010 reveals metabolic pathways for host-derived glycan foraging. Proc National Acad Sci 107:19514-19519

Turroni F, Ventura M, Buttó LF, Duranti S, O’Toole PW, Motherway MOC, van Sinderen D (2014) Molecular dialogue between the human gut microbiota and the host: a Lactobacillus and Bifidobacterium perspective. Cell Mol Life Sci 71:183-203 
Utomo B, Rosyidi D, Radiati LE, Puspaningsih NNT, Proborini WD (2014) Protein characterization of extracted water from three kinds of edible bird nest using SDS-PAGE CBB staining and SDS-PAGE glycoprotein staining and LC-MS/MS analyses. IOSR J Agr Vet Sci 7:33-38

Van der Meulen R, Makras L, Verbrugghe K, Adriany T, De Vuyst L (2006) In vitro kinetic analysis of oligofructose consumption by Bacteroides and Bifidobacterium spp, indicates different degradation mechanisms. Appl Environ Microbiol 72:1006-1012

Walker WA (2017) The importance of appropriate initial bacterial colonization of the intestine in newborn, child, and adult health. Pediatr Res 82:387

Walker AW, Duncan SH, Leitch ECM, Child MW, Flint HJ (2005) pH and peptide supply can radically alter bacterial populations and short-chain fatty acid ratios within microbial communities from the human colon. Appl Environ Microbiol 71:3692-3700

Whitman WB, Bowen TL, Boone DR (2006) The methanogenic bacteria. Prokaryotes 3:165-207

Wieruszeski JM, Michalski JC, Montreuil J, Strecker G, Peter-Katalinic J, Egge H, Van Halbeek H, Mutsaers JH, Vliegenthart JF (1987) Structure of the monosialyl oligosaccharides derived from salivary gland mucin glycoproteins of the Chinese swiftlet (genus Collocalia). J Biol Chem 262:6650-6657
Xian XM, Hou Y, Lin JR, Huang S, Lai XP, Chen JN (2010) Study on degradation of protein of the edible birds' nest (Aerodramus) in vitro. J Chin Med Mat 33:1760-1763

Yagi H, Yasukawa N, Yu SY, Guo CT, Takahashi N, Takahashi T, Bukawa W, Suzuki T, Khoo KH, Suzuki Y, Kato K (2008) The expression of sialylated high-antennary N-glycans in edible bird's nest. Carbohydr Res 343:1373-1377

You Y, Cao Y, Guo S, Xu J, Li Z, Wang J, Xue C (2015) Purification and identification of $\alpha 2-3$ linked sialoglycoprotein and $\alpha 2-6$ linked sialoglycoprotein in edible bird's nest. Eur Food Res Technol 240: 389-397

Yu ZT, Chen C, Kling DE, Liu B, McCoy JM, Merighi M, Heidtman M, Newburg DS (2012) The principal fucosylated oligosaccharides of human milk exhibit prebiotic properties on cultured infant microbiota. Glycobiology 23:169-177

Zhu L, Qin S, Zhai S, Gao Y, Li L (2017) Inulin with different degrees of polymerization modulates composition of intestinal microbiota in mice. FEMS Microbiol Lett 364

Zimmer J, Lange B, Frick JS, Sauer H, Zimmermann K, Schwiertz A et al (2012) A vegan or vegetarian diet substantially alters the human colonic faecal microbiota. Eur J Clin Nutr 66:53-60

Publisher's note Springer Nature remains neutral with regard to jurisdictional claims in published maps and institutional affiliations. 